\title{
Effect of Exercise on Metabolic Disorders Associated with Obesity
}

\author{
ASMAA S.Y. MOHAMED, M.Sc.; RANIA N. ABD EL-LATIF, M.D.; \\ SOHA S. ZAKARIA, M.D. and THANAA F. EL-SHEIKH, M.D. \\ The Department of Medical Biochemistry, Faculty of Medicine, Tanta University, Tanta, Egypt
}

\begin{abstract}
Background: The epidemic of obesity has contributed to the rapid rise in comorbid conditions such as cardiovascular disease, type 2 diabetes mellitus and hypertension.

Aim of Study: The aim of this study was to determine the effect of exercise on metabolic disorders and mitochondrial dysfunction associated with obesity.

Material and Methods: The study was conducted on 60 male albino rats divided randomly into four equal groups: Group I: Control non-trained group; Group II: Obese nontrained group; Group II: Control trained group and Group IV: Obese trained group. Obesity was induced by hydrating rats with $70 \%$ fructose solution for 5 weeks. Following induction of obesity and after 8 consecutive weeks of swimming exercise, citrate synthase enzyme activity was measured by a kinetic spectrophotometric assay. Plasma insulin level was measured by ELISA and insulin resistance was assessed using (HOMAIR index), while plasma levels of glucose, triglycerides and total cholesterol were determined by colorimetric assay.
\end{abstract}

Results: The levels of glucose, total cholesterol, triglycerides and insulin resistance were significantly increased in obese non-trained group but significantly decreased in obese trained group compared to control groups. Also citrate synthase activity was significantly increased in obese trained group compared to obese non-trained group.

Conclusion: Endurance exercise results in improvement of obesity and glucose homeostasis.

Key Words: Obesity - Metabolic syndrome - Mitochondrial dysfunction - Citrate synthase enzyme - HOMAIR index.

\section{Introduction}

OBESITY has rapidly become a worldwide epidemic. In parallel, the prevalence of obesity-related comorbid conditions has also escalated, including insulin resistance, metabolic syndrome, type 2 diabetes mellitus, hypertension, chronic kidney disease, cardiovascular disease and cancer. Obesity

Correspondence to: Dr. Asmaa S.Y. Mohamed, E-Mail: Dr.Asma 14@yahoo.com is primarily a consequence of unhealthy diet and lack of physical activity and the modern best practice treatment of obesity includes increasing physical activity and behavior modification [1,2] .

Although obesity is most commonly caused by excess energy consumption (dietary intake) relative to energy expenditure (energy loss via metabolic and physical activity), the etiology of obesity is highly complex and includes genetic, physiologic, environmental, psychological, social and economic factors that interact in varying degrees to promote the development of obesity [3]

Added sweeteners are important components of our diet. Sweet corn-based syrups were developed during the past three decades, and now represent close to one-half of the caloric sweeteners. Fructose is sweeter than sucrose, so it became the sweetener of choice for the soft drink and ice cream industries. Excessive consumption of added sugars contributes to rising obesity and diabetes rates by increasing plasma free fatty acids, leptin, abdominal adipose tissue and impaired insulin sensitivity $[4,5]$

Obesity is an exaggeration of normal adiposity. It is a major contributor to the metabolic dysfunction involving lipid and glucose, on a broader scale. Excess adipocytes secrete numerous cytokines that contribute to vascular dysfunction in hypertension and dyslipidemia, as manifested by hypercholesterolemia and triglyceridemia. These conditions eventually contribute to significant atherosclerosis, and when associated with obesity and diabetes, they constitute the metabolic syndrome [6] .

It was found that obesity is associated with mitochondrial dysfunction. Citrate synthase enzyme is one of the key regulatory enzymes in the energygenerating metabolic pathways and it catalyzes the condensation of acetyl coenzyme A and oxaloacetate to form citrate in the TCA cycle. Moreover, it 
is a metabolic marker of the oxidative and respiratory capacity in skeletal muscles [7]

Exercise is an effective approach for prevention and treatment of obesity by increasing energy expenditure, and it has long been recognized for its pluripotent effects on body composition, metabolic health, cardiovascular disease, and mental health. Skeletal muscle is the major target organ that participates in exercise. It is widely accepted that a motility factor is released during skeletal muscle contraction, which may improve muscle function $[8]$

The expected outcome of this study is to determine the effect of exercise on metabolic disorders and mitochondrial dysfunction associated with obesity.

\section{Material and Methods}

\section{Chemicals:}

Most chemicals including dithiobis 2nitrobenzoate (DTNB), acetyl-CoA, oxaloacetate (OAA), were purchased from Sigma-Aldrich Chemical Co., St. Louis, MO, USA.

\section{Study design and animal grouping:}

This study was carried out in Medical Biochemistry Department, Faculty of Medicine, Tanta University, Egypt, in accordance with guidelines of the Ethical Committee of Faculty of Medicine, Tanta University, Egypt (approval code 31088/07/ 16) starting from September 2016 to December 2017.

This study was carried out on 60 male albino rats weighing $100-150 \mathrm{~g}$. The studied animals were divided randomly into two groups each comprised 30 rats:

- Group I (control group): Rats in this group received standard caloric diet (consisting of 59.7\% carbohydrates, $10.6 \%$ fat, and $27.3 \%$ protein), and had free access to plain water for 5 weeks.

- Group II (obese group): Rats in this group received standard caloric diet, and had free access to water containing $70 \%(\mathrm{w} / \mathrm{v}) \mathrm{D}$-fructose for 5 weeks to induce obesity [9]. D-fructose was supplied by Sigma-Aldrich Co. LLC, USA. The Dfructose-enriched drinking water was changed twice a week.

\section{After obesity induction (5 weeks):}

Control group were equally divided into:

- Group I (control non-trained) and Group II (control trained).

\section{Obese group were similarly divided into:}

- Group II (obese non-trained) and Group IV (obese trained).

Rats of both control and obese trained groups underwent forced swimming exercise according to the following regimen:

Swimming exercise was performed 5 days a week for 8 successive weeks without a load in a barrel filled with water at $33-35^{\circ} \mathrm{C}$ to a depth of $40-50 \mathrm{~cm}$, which allowed free swimming. The animals in the exercised groups were trained to reduce the stress of swimming by gradually increasing time from 1, 5, 10, 15 till 30min [10].

\section{Blood and tissue sampling:}

At the end of the experimental period (13 weeks), all rats were weighed and sacrificed. Blood samples obtained after cervical decapitation were collected in sterile EDTA-containing tubes. Following immediate centrifugation at 5000rpm for 20min, plasma was separated by dry clean Pasteur pipettes in eppendorf tubes, and the samples were labeled and frozen at $-20^{\circ} \mathrm{C}$ until analysis. Soleus and gastrocnemius muscles of the different groups were dissected carefully, washed three times with ice cold saline, weighed and blotted individually on ash-free filter paper, and cut into small pieces, then stored at $-20^{\circ} \mathrm{C}$ till used for preparation of mitochondrial subsamples.

Preparation of mitochondria from muscle tissue [11]:

One piece (50mg) of muscle tissue was sampled, immediately washed with phosphate-buffered saline, and homogenized in $1 \mathrm{ml}$ mitochondrial isolation buffer $(0.01 \mathrm{M}$ Tris- $\mathrm{HCl}, 0.0001 \mathrm{M}$ EDTA-2Na, $0.01 \mathrm{M}$ sucrose, $0.8 \% \mathrm{NaCl}, \mathrm{pH} 7.4$ ) with a PotterElvenhjem tissue homogenizer (20-30 up and down strokes). The homogenate was centrifuged at 1500 $\mathrm{rpm}$ for 5 minutes at $4 \mathrm{C}$. the resultant supernatant was collected and then centrifuged again at 10.000 $\mathrm{rpm}$ for $15 \mathrm{~min}$. The precipitate is the mitochondria from muscle tissue.

\section{Biochemical analysis:}

1-Measurement of plasma glucose level [12]: By enzymatic colormetric glucose oxidase method according to Trinder, 1969 using a commercial kit obtained from BIOMED Diagnostics Company, Germany. The results were expressed as $\mathrm{mg} / \mathrm{dl}$.

2- Estimation of Total Cholesterol (TC) level [13]: By enzymatic colorimetric method using commercial kit supplied by BIOMED Diagnostics 
Company, Germany. Cholesterol is determined after enzymatic hydrolysis and oxidation.

3-Estimation of Triglycerides (TG) level [14]: By enzymatic colorimetric method using commercial kit supplied by BIOMED Diagnostics Company, Germany.

4- Measurement of insulin level $[15,16]$ : The levels of insulin in plasma were determined by a commercial Enzyme-Linked Immune-Sorbent Assay (ELISA) kit obtained from SunRed Biological Technology Co., Ltd, Shanghai. China with catalogue No: 201-11-0708, and according to the manufacturer's instructions. The levels were expressed as mIU/L. Insulin resistance was assessed using the homeostasis model assessment index for insulin resistance (HOMA-IR index) using Matthews's equation as follow [17]

$\mathrm{IRI}=\frac{\text { Fasting insulin }(\mathrm{mIU} / \mathrm{L}) \mathrm{X} \text { Fasting glucose }(\mathrm{mg} / \mathrm{dl})}{405}$

5- Measurement of citrate synthase activity in muscle tissue by acolorimetricc assay [18]: Citrate synthase activity was measured by a colorimetric assay that is based on the reaction between 5', 5'-Dithiobis 2-nitrobenzoic acid (DTNB) and CoA-SH to form TNB according to the method described bySreree PA (1969). In brief,200 of mitochondrial subsample was added to 800 of mixture containing $0.1 \mathrm{mMM} 5$,5-dithio-bis-(2nitrobenzoic) acid, $0.5 \mathrm{mM}$ oxaloacetate, 50 EDTA, $0.31 \mathrm{mM}$ acetyl coenzyme A, $5 \mathrm{mM}$ triethanolamine hydrochloride, and0. 1MMTris$\mathrm{HCl}, \mathrm{pH} 8.1$. The activity of citrate synthase was measured spectrophotometrically at $412 \mathrm{~nm}$ and $30^{\circ} \mathrm{C}$.. The amounts of TNB produced were calculated using a molar extinction coefficient $\varepsilon=136000 \mathrm{M}^{-1} \mathrm{~cm}^{-1}$

Protein content was measured by colorimetric method using commercially available kit supplied by Diamond Diagnostics Company [19] .

\section{Statistical analysis:}

Statistical presentation and analysis of the results of the present study was conducted, and the data were presented as mean \pm SD using statistical package for the social sciences, Version 20.0 for Windows (SPSS; SPSS Inc., Chicago, Illinois, USA). One-way analysis of variance (ANOVA) and Tukey tests were calculated for multiple comparisons to evaluate the statistical significance between the experimentalgroups., $p$-value less than 0.05 was considered significant.

\section{Results}

Table (1) showed the changes in body weight among all studied groups along the course of the study: In control groups (Group I, and III) mean initial body weights were 110.4 , and $126.3 \mathrm{~g}$ respectively. After 5 weeks, the percent increases in mean body weight were $45 \%$, and $39.5 \%$ respectively. After further 8 weeks, control rats not performing exercise gained further $61 \%$ increase in body weight, while those performing exercise for 8 weeks, the percent increase in body weight was only $29.7 \%$. In rats subjected to fructose induced obesity (Group II, and IV) the body weight gain after 5 weeks was $135 \%$ and $161.9 \%$ higher than the initial weight. Fructose-induced obese rats not performing exercise (Group II) showed further increase $13.6 \%$ in their final body weight when compared to that measured after 5 weeks. On the other hand, exercise evoked $29.5 \%$ decrease in body weight in Group IV (obese rats performing exercise).

Table (1): Changes in body weight (in grams) in different studied groups along the course of the study.

\begin{tabular}{|c|c|c|c|}
\hline Body weight (g) & $\begin{array}{c}\text { Initial body } \\
\text { weight }\end{array}$ & $\begin{array}{l}\text { Body weight } \\
\text { after } 5 \text { weeks }\end{array}$ & $\begin{array}{c}\text { Final } \\
\text { body weight }\end{array}$ \\
\hline $\begin{array}{l}\text { Group I } n=15: \\
\text { Range } \\
\text { Mean } \\
\text { Change } \%\end{array}$ & $\begin{array}{l}93 .-148 \\
110.4\end{array}$ & $\begin{array}{l}143-198 \\
160.4 \\
\uparrow * 45 \% \%\end{array}$ & $\begin{array}{l}222-288 \\
258.2 \\
\uparrow * * 61 \% \%\end{array}$ \\
\hline $\begin{array}{l}\text { Group II } n=15: \\
\text { Range } \\
\text { Mean } \\
\text { Change } \%\end{array}$ & $\begin{array}{l}109-145 \\
125.9\end{array}$ & $\begin{array}{l}270-335 \\
295.7 \\
\uparrow * 135 \% \%\end{array}$ & $\begin{array}{l}290-390 \\
336 \\
\uparrow * * 13.6 \% \%\end{array}$ \\
\hline $\begin{array}{l}\text { Group III } n=15: \\
\text { Range } \\
\text { Mean } \\
\text { Change \% }\end{array}$ & $\begin{array}{l}95-150 \\
126.3\end{array}$ & $\begin{array}{l}145-200 \\
176.3 \\
\uparrow * 39.5 \% \%\end{array}$ & $\begin{array}{l}160-280 \\
228.6 \\
\uparrow * * 29.7 \% \%\end{array}$ \\
\hline $\begin{array}{l}\text { Group IV } n=15: \\
\text { Range } \\
\text { Mean } \\
\text { Change } \%\end{array}$ & $\begin{array}{l}104-145 \\
128\end{array}$ & $\begin{array}{l}255-390 \\
335.3 \\
\uparrow * 161.9 \%\end{array}$ & $\begin{array}{l}170-290 \\
236.4 \\
\downarrow * * 29.5 \%\end{array}$ \\
\hline $\begin{array}{ll}\text { Group I } & : \text { Control } \\
\text { Group II } & \text { : Obese } \mathrm{n} \\
\text { GroupIH } & \text { : Control } \\
\text { Group IV } & : \text { Obese t } \\
* * & : \text { Body w } \\
* * & : \text { Final bc }\end{array}$ & $\begin{array}{l}\text { non-trained gr } \\
\text { n-trained grou } \\
\text { rained group. } \\
\text { ained group. } \\
\text { ight after } 5 \text { we } \\
\text { dy weight vs. }\end{array}$ & $\begin{array}{l}\text { ks vs initial bo } \\
\text { dy weight afte }\end{array}$ & $\begin{array}{l}\text { weight. } \\
\text { weeks. }\end{array}$ \\
\hline
\end{tabular}

Table (2) showed: Plasma levels of glucose, total cholesterol and triglycerides and insulin resistance were significantly increased in obese nontrained group but significantly decreased in obese trained group as compared to control groups. Also citrate synthase activity was significantly increased in obese trained group and significantly decreased in obese non-trained group compared to control group. 
Table (2): Comparative statistics of studied biomarkers between all groups.

\begin{tabular}{lllllll}
\hline Parameters & \multicolumn{1}{c}{ Group I } & \multicolumn{1}{c}{ Group II } & Group III & Group IV & F & $p$-value \\
\hline - Plasma TG mg/dl & $80.8 \pm 20.682$ & $239.7 \pm 108.470$ & $79.9 \pm 21.107$ & $156.5 \pm 41.981$ & 24.068 & $<0.001^{*}$ \\
- Plasma TC mg/dl & $86 \pm 24.847$ & $132.8 \pm 41.933$ & $104 \pm 17.184$ & $90.9 \pm 27.572$ & 7.720 & $<0.001^{*}$ \\
- Plasma glucose mg/dl & $112.5 \pm 14.750$ & $175.5 \pm 38.794$ & $118.9 \pm 24.993$ & $138.1 \pm 29.751$ & 14.906 & $<0.001^{*}$ \\
- Plasma insulin (mIU/L) & $0.557 \pm 0.006$ & $0.558 \pm 0.010$ & $0.557 \pm 0.006$ & $0.557 \pm 0.005$ & 0.131 & 0.941 \\
- Insulin resistance (HOMA-IR) & $0.155 \pm 0.022$ & $0.238 \pm 0.055$ & $0.163 \pm 0.034$ & $0.190 \pm 0.041$ & 13.493 & $<0.001 *$ \\
- Muscle tissue CS activity & $8.237 \pm 3.392$ & $3.183 \pm 1.057$ & $10.768 \pm 3.259$ & $26.698 \pm 5.920$ & 106.093 & $<0.001^{*}$ \\
$\quad$ (nmol/min/mg protein) & & & & & & \\
\hline
\end{tabular}

Data are mean \pm SD of a group of 20 rats.

Statistical analysis is carried out using one-way analysis of variance with Tukey's test.

TG : Total Triglycerides.

TC : Total Cholesterol.

HOMA-IR : Homeostasis Model Assessment Index for Insulin Resistance.

CS : Citrate Synthase.

: Significant $p$-value $(<0.05)$.

\section{Discussion}

In this study, obesity has been induced in rats by keeping them on high fructose intake for 5 weeks and a significant increase in body weight has been observed in these rats (Group II, and IV) when compared to those groups receiving fructose free diet (Group I, and III). Meanwhile alterations in lipid profile in the form of hypertriglyceridemia and hypercholesterolemia have been also detected in the sera of rats kept on high fructose hydration. These findings can indicate successful induction of obesity in these rats.

These findings are supported by Bocarsly et al., who provided an evidence of accumulation of adipose tissue in the abdominal area of male and female rats fed on high fructose diet. They also reported the presence of hypertriglyceridemia in the sera of these rats [20]. Furthermore, some studies in humans have also shown an increase in serum triglyceride levels in individuals consuming high fructose diet [21,22]. Silbernagel and colleagues demonstrated that after consuming $150 \mathrm{~g}$ of fructose daily for 4 weeks, subjects presented an elevation of $350 \mathrm{mg} / \mathrm{dl}$ of serum triglyceride levels when compared to those consuming the same amount of glucose [21].

The role of fructose in the induction of obesity can be explained on the fact that fructose metabolism in liver and its conversion to pyruvate through the glycolytic pathway is bypassing the rate limiting step of glycolysis, namely phosphofructokinase1. Thus the increased flow of pyruvate to the mitochondria of hepatocytes with the subsequent formation of acetyl CoA and oxaloacetate will stimulate citrate synthase to catalyze the condensation of these two metabolic intermediates to form citrate, which when in excess will be translocated to the cytosol to be splitted into acetyl CoA and oxaloacetate. The former will be forwarded directly for de novo synthesis of fatty acids and cholesterol $[23,24]$

Insulin resistance and metabolic syndrome are the most striking complications of obesity. Insulin resistance is always claimed whenever insulin fails to elicit a normal physiological response and individuals with insulin resistance are always presented with hyperglycemia in face of normal or even higher than normal insulin levels. HOMA-IR (homeostasis model assessment index for insulin resistance) is now considered as a monitor of insulin resistance [25].

In this current study, rats kept on high fructose hydration (Group II) showed higher plasma glucose levels along the course of fructose intake when compared to control group (Group I), although their insulin levels were not statistically different. Also insulin resistance in those rats has been confirmed by presence of higher HOMA-IR values in Group II rats.

This finding is supported by those reported by Thomas et al., (2015) and Lin et al., (2016) who observed that high fructose consumption was associated with higher levels of fasting glucose, insulin resistance, and central adiposity [26,27].

The relationship between muscle exercise, glucose homeostasis and lipid metabolism has long been established. Resting muscles consume 10\% of circulating Free Fatty Acids (FFA) mobilized from adipose tissue by Hormone Sensitive Lipase (HSL) during late fasting and starvation. These FFA have sparing effect on glucose in muscles as resting muscles prefer FA for energy production than glycogenolysis. Meanwhile FFA block glucose 
uptake by myocytes secondary to their blocking effect on GLUT4 transporters by a mechanism depending on the excitatory effect of FFA on release of nuclear factor Kappa B [NF- кB]. Also excess translocation of long chain acyl CoA to mitochondrial matrix for 3 -oxidation exerts an inhibitory effect on pyruvate dehydrogenase enzyme complex (PDH) by activating PDH kinase component of PDH complex regulatory subunit [23]. This spares blood glucose for brain and RBCs nutrition. Exercising skeletal muscles on the other hand improve glycemic control in well fed individuals through improving insulin action and glucose metabolism. Exercise dependent acceleration of GLUT4 trafficking by $\mathrm{Ca}^{+2}$ dependent mechanism [28], and also exercise enhancement of insulin sensitivity has been observed. A subsequent stimulation of intracellular enzymes of glucose metabolism e.g. hexokinase and glycogen synthase will result in attracting most glucose of the well fed animals to be taken up by the large bulk of skeletal muscles and hence preventing overflow of glucose to adipose tissue and fat formation [23,24]

This study has been conducted to elucidate the effect of exercise on weight gain, lipid profile and insulin resistance in rats with fructose induced obesity compared to control non obese group. In groups practicing exercise, rats had been subjected to forced swimming 5 days a week for 8 weeks after induction of obesity.

In this current study and after 8 weeks of exercise, the control group practicing exercise (Group III) showed lower rate of weight gain when compared to control group not subjected to exercise (Group I). In fructose consuming group the nontrained group (Group II) showed $13.6 \%$ increase in body weight (during the period of exercise) in face of $29.5 \%$ decrease in body weight in obese trained group (Group IV). This indicates that exercise induces weight loss in obese and non-obese rats, although the effect is more profound in obese rats. Also exercise dependent lowering effect on lipid profile in obese rats was also manifested as significant lower values of serum TG and TC in obese trained rats compared to non-trained. Also very significant lower levels of blood glucose have been reported in obese trained rats when compared to their corresponding non-trained group and improvement of insulin resistance in the form of significantly lower HOMA-IR values has been reported in obese trained group.

These exercise induced improvement in body weight, glucose hemostasis and lipid profile can in part be explained on the basis of the relationship between muscle exercise and enhancement of glucose uptake by the large bulk of muscles, until recently proved that exercising muscles act as an endocrine system and secrete a number of factors named myokines that exert a profound effect on glucose and fatty acid metabolism [23,24]

Citrate synthase enzyme is one of the key regulatory enzymes in the energy-generating metabolic pathways and it catalyzes the condensation of acetyl coenzyme A and oxaloacetate to form citrate in the TCA cycle. It is a metabolic marker of the oxidative and respiratory capacity in skeletal muscles [7]

In this study, the citrate synthase activity in soleus muscle was highest in the obese trained group (Group IV) and lowest in the obese group (Group II) compared to control groups (Group I, III), suggesting that endurance exercise training increases the skeletal muscle oxidative capacity and the activities of mitochondrial enzymes. This is in agreement with Kim et al., (2014) who suggested that endurance exercise training increased oxidative capacity of skeletal muscles [29].

Adaptive elevation in the mitochondrial protein content by exercise training is suggested to be due to an increase in the rate of protein synthesis rather than a decrease in the rate of protein degradation. This raises the possibility that the modulation of mitochondrial enzyme expression is in response to exercise. Exercise requires an expenditure of energy above resting levels. Energy substrates are utilized by energy-generating metabolic pathways, including glucose utilization, liver glycogenolysis, lipolysis, and tricarboxylic acid cycle [30]. Exercise leads to decreased energy sources due to the enhanced utilization of energy substrates, so the mRNA expression of fatty acid oxidation-related genes (PPARy and CPT 1) were significantly upregulated and the activity of CS tended to increase in the soleus muscle [29].

\section{Conclusion:}

Fructose consumption promotes disturbances in glucose metabolism, and alterations in the lipid profile, which is associated with an inflammatory response and alterations in the redox state, that leads to obesity and implies a systemic picture of insulin resistance. Exercise benefits a variety of organ systems in mammals; exercise cause an increase in energy expenditure in rats through improvement of mitochondrial function reflected by increasing citrate synthase activity. This results in improvement of obesity, glucose and lipid homeostasis. 
Financial support and sponsorship: Nil.

\section{Conflicts of interest:}

There are no conflicts of interest.

\section{References}

1- FLEGAL K.M., CARROLL M.D., OGDEN C.L., et al.: Prevalence and trends in obesity among US adults, 19992008. J.A.M.A., 303 (3): 235-41, 2010.

2- OGA E.A. and ESEYIN O.R.: The Obesity Paradox and Heart Failure: A Systematic Review of a Decade of Evidence. J. Obes., 9040248: 1-9, 2016.

3- WRIGHT S.M. and ARONNE L.J.: Causes of obesity. Abdom Imaging, 3 7: 73 0-2, 2012.

4- STANHOPE K.L.: Sugar consumption, metabolic disease and obesity: The state of the controversy. Crit. Rev. Clin. Lab. Sci., 2016 (53): 52-67, 2016.

5- TOOP C.R. and GENTILI S.: Fructose Beverage Consumption Induces a Metabolic Syndrome Phenotype in the Rat: A Systematic Review and Meta-Analysis. Nutrients, 8 (9): 1-15, 2016.

6- SHIRAI K.: Obesity as the core of the metabolic syndrome and the management of coronary heart disease. Curr. Med. Res. Opin., 20: 295-304, 2004.

7- SPINA R.J., CHI M.M.Y., HOPKINS M.G., et al.: Mitochondrial enzymes increase in muscle in response to 710 days of cycle exercise. J. Appl. Physiol., 80: 2250-4, 1996.

8- RICHTER E.A. and HARGREAVES M.: Exercise, GLUT4, and skeletal muscle glucose uptake. Physiol. Rev., 93: 993-1017, 2013.

9- PEDERSEN B.K. and FEBBRAIO M.A.: Muscles, exercise and obesity: Skeletal muscle as a secretory organ. Nature Reviews Endocrinology, 8 (8): 457-65, 2012.

10- ZIOLKOWSKI W., FLIS D.J., HALON M., et al.: Prolonged swimming promotes cellular oxidative stress and p66Shc phosphorylation but does not induce oxidative stress in mitochondria in the rat heart. Free Radical Research, 49 (1): 7-16, 2015.

11- DING J., YU H.L., MA W.W., et al.: Soy Isoflavone Attenuates Brain Mitochondrial Oxidative Stress Induced by Beta-Amyloid Peptides 1-42 Injection in Lateral Cerebral Ventricle. Journal of Neuroscience Research, 91: 562-7, 2013.

12- TRINDER P.: Determination of blood glucose using an oxidase peroxidase system with a non-carcinogenic chromogen. J. Clin. Pathol., 22 (2): 158-61, 1969.

13-RICHMOND W.: Enzymatic determination of cholesterol. Clin. Chem., 19: 1350-6, 1973.

14- FOSSATI P. and PRENCIPE L.: Serum triglycerides determined colometrically with an enzyme that produces hydrogen peroxide. Clin. Chem., 28: 2077-80, 1982.

15- CHEUNG A.T., DAYANANDAN B., LEWIS J.T., et al.: Glucose-dependent insulin release from genetically engineered K cells. Science, 290: 1959-62, 2000.
16- DUTTAROY A., ZIMLIKI C.L., GAUTAM D., et al.: Muscarinic stimulation of pancreatic insulin and glucagon release is abolished in $\mathrm{m} 3$ muscarinic acetylcholine receptor-deficient mice. Diabetes, 53: 1714-20, 2004.

17- MATTHEWS D.R., HOSKER J.P., RUDENSKI A.S., et al.: Homeostasis model assessment: Insulin resistance and 3 -cell function from fasting plasma glucose and insulin concentrations in man. Diabetologia, 28: 412-9, 1985.

18- SRERE P.A.: Citrate synthase. Methods Enzymol., 13: 3$5,1969$.

19- GORNALL A.G., BARDAWILL C.J. and DAVID M.M.: Determination of serum proteins by means of the biuret reaction. J. Biol. Chem., 177 (2): 751-66, 1949.

20- BOCARSLY M.E., POWELL E.S., AVENA N.M., et al.: High-fructose corn syrup causes characteristics of obesity in rats: Increased body weight, body fat and triglyceride levels. Pharmacol. Biochem. Behav., 97: 101-6, 2010.

21- SILBERNAGEL G., MACHANN J., UNMUTH S., et al.: Effects of 4-week very-high fructose/glucose diets on insulin sensitivity, visceral fat and intrahepatic lipids: An exploratory trial. Br. J. Nutr., 2011 (106): 79-86, 2011.

22- ABDEL-SAYED A., BINNERT C. and LÊ K.A.: Highfructose diet impairs basal and stress-mediated lipid metabolism in healthy male subjects. Br. J. Nutr., 100: 393-9, 2008.

23- DEVLIN T.M.: Textbook of Biochemistry: With Clinical Correlations. 18ed. Hoboken, N.J.: John Wiley \& Sons, 2011.

24- RODWELL V.W., BENDER D., BOTHAM K.M., et al.: Harper's Illustrated Biochemistry. McGraw-Hill Education/ Medical, 30 edition. ISBN: 0071825347/9780071825344, 2015.

25- GALLAGHER E.J., LEROITH D. and KARNIELI E.: Insulin resistance in obesity as the underlying cause for the metabolic syndrome. Mt. Sinai J. Med., 77 (5): 511 23, 2010.

26- THOMAS S., SENTHILKUMAR G.P., SIVARAMAN K., et al.: Effect of s-methyl-L-cysteine on oxidative stress, inflammation and insulin resistance in male wistar rats fed with high fructose diet. Iran. J. Med. Sci., 2015 (40): 45-50, 2015.

27- LIN W.T., CHAN T.F., HUANG H.L., et al.: FructoseRich Beverage Intake and Central Adiposity, Uric Acid, and Pediatric Insulin Resistance. J. Pediatr., 171: 90-6, 2016.

28- MÎINEA C.P., SANO H., KANE S., et al.: AS160, the Akt substrate regulating GLUT4 translocation, has a functional Rab GTPase-activating protein domain. Biochem. J., $391:$ 87-93, 2005.

29- KIM Y., YOO S., CHAE C., et al.: Omija Fruit Extract Improves Endurance and Energy Metabolism by Upregulating PGC-1a Expression in the Skeletal Muscle of Exercised Rats. J. Med. Food, 17 (1): 28-35, 2014.

30- HIRABARA S.M., SILVEIRA L.R., ABDULKADER F.R., et al.: Role of fatty acids in the transition from anaerobic to aerobic metabolism in skeletal muscle during exercise. Cell Biochem. Funct., 2006 (6): 475-81, 2006. 


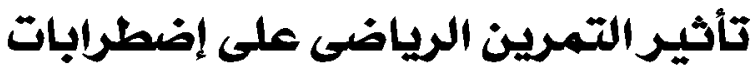

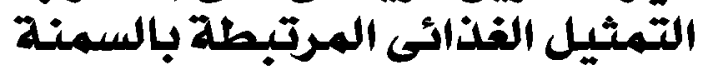

يعد مرض السمنة مشكلة صحية عالمية، ثبت آنها مرتبطة بزيادة خطر الإصابة بآمراض القلب والآوعية الدموية والسكتة الدماغية، والموت.

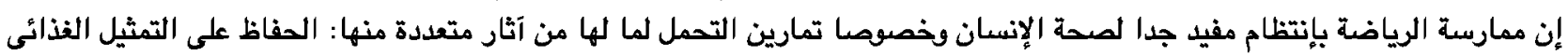

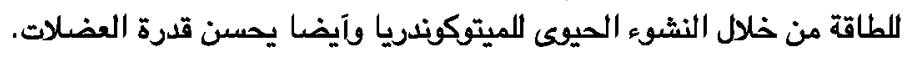

$$
\text { الهدف من هذه الدراسة: تقييم دور الرياضة على السمنة المفتعلة بالفركتو فى الجرذان. }
$$

وقد آجريت هذه الدراسة على: .7 من الجرذان. تم تقسيمهم إلى: مجموعة ا(ضابطة غير مدربة)، مجموعة ب (مصابة بالسمنة غير

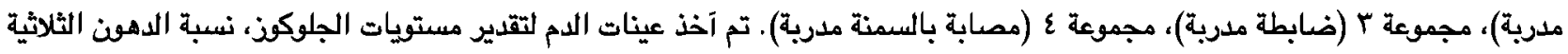

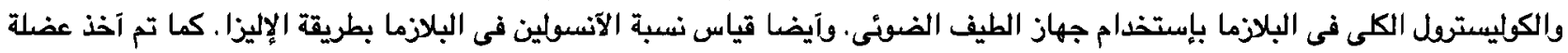

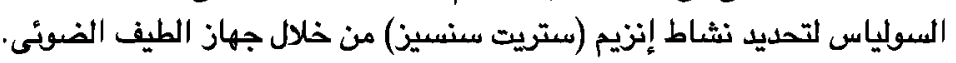

وقذ آسفرت النتائج عن: زيادة ملحوظة فى مستوى سكر الجلوكون نسبة الدهون الثلاثية والكوليسترل الكلى مع إرتقاع مؤثر مقاومة

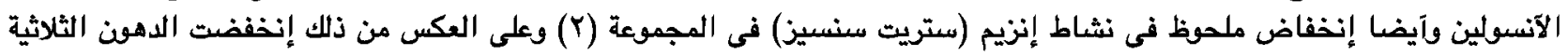

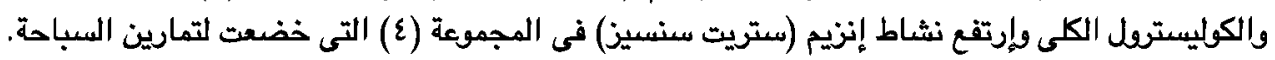

وعلى آساس هذه النتائج: يمكن آن نستخلص آن التمارين الرياضية لها دور فعال فى تحسن مرض السمنة الناتج عن إعطاء الفركتون الجرزان. 